\title{
sciendo
}

\section{Resource abundance as an indicator of economic development in selected countries}

\author{
Mădălina Andreea HODOR \\ Bucharest University of Economic Studies, Bucharest, Romania \\ madalinahodor@gmail.com \\ Roxana CLODNITCHI \\ Bucharest University of Economic Studies, Bucharest, Romania \\ roxana.clodnitchi@fabiz.ase.ro
}

\begin{abstract}
The efficiency of resources is a current issue that can be of great interest to anyone, especially since it is often associated with economic performance, at both - micro and macro level. Therefore, it can be useful to evaluate the resource availability of countries and to understand how a country's economic development is connected with its resource abundance. Our study examines whether the availability of resources can be viewed as an indicator of the economic development of a particular country by analysing the correlation between the total resources rent, as calculated by the World Bank, and the gross domestic product and its development in 45 countries worldwide. We found that natural resources rents are linked to both GDP per capita and GDP growth, leading often to strong positive or negative correlations. The particular cases need to be further addressed, by looking into additional parameters on country and regional level.
\end{abstract}

Keywords: resource efficiency, resource rents, correlations.

Acknowledgement: This work was cofinanced from the European Social Fund through Operational Programme Human Capital 2014-2020, project number POCU/380/6/13/125015 "Development of entrepreneurial skills for doctoral students and postdoctoral researchers in the field of economic sciences"

\section{Introduction}

Economic development in a contemporary environment encompasses a wide range of parameters. The degree of economic development of the countries can also be explained by the effect of the abundance of natural resources on economic growth. The number of authors looking into this relation is however limited. Yanikkaya and Turan (2018) separated countries into developing and industrialised countries. They showed within their research that for both, developing and industrialised countries, rents on natural gas, oil and coal had a significantly positive effect on growth, while forest rents had a negative effect.

The World Bank's 2006 classification for low-, middle-, and high-income countries was used by Kim and Lin (2017) to distinguish between countries. Middle-income countries were most affected by the so-called "resource curse" (particularly dependence on agricultural and nonagricultural primary exports), while lower-middle-income countries suffered the least damage from increased dependence on natural resources (particularly agricultural and non-agricultural).

In contrast to openness to trade and institutional quality, these findings seem to suggest that more developed countries are more affected by the abundance of natural resources than developing countries. (Trumel and Muhammad, 2020)

When talking about development indicators, one can find more than 60 indicators that can be grouped into different categories, namely: Economic Growth, Household Income and

DOI: $10.2478 /$ picbe-2021-0021

(C) 2021 M. A. Hodor, R. Clodnitchi, published by Sciendo.

This work is licensed under the Creative Commons Attribution 4.0 License. 
Expenditure, Corporate Profits and Investment, Labor, Inflation and Deflation, Production, Housing, Finance, Government, international, cyclical indicators and forecasts, economic wellbeing and psychology (Frumkin, 2006).

For the purposes of this work, the PIB / head and economic growth were chosen. Gross domestic product is used to indicate what is happening in the macroeconomic environment. The growth figures attract a lot of attention from policymakers, as GDP growth is very often one of the most important economic goals of a country. Partly because of the importance of GDP, economists play a very important role in society (Cobb et al., 1995; Amoah et al., 2021).

\section{Research method and evaluation}

The aim of this study was to determine whether the use of natural resources can serve as an indicator of the economic development of certain countries. To that end, this paper aimed to establish a set of correlations between a country's GDP per capita (in USD) and total resource rents (as a\% of GDP), as well as between GDP growth (in\%) and total resource rents (in\% of GDP).

For this purpose, two research methods were used as described below.

\section{Literature review}

A literature review examines scientific articles, books, dissertations, organisational discussions, and other resources that may be relevant to the selected topic of the paper. In the literature review, the previous work and discoveries were taken into account and discussed.

The aim of the literature review was to create a context for the influence of the use of natural resources on the economic development of a country. This topic has been debated for a long time and is already an interesting topic at the moment of writing this paper.

Numerous scientists discussed the importance of resources and even the dependence on resources in different countries. Thorvaldur Gylfalson, for example, in his study "Natural Resources and economic growth: from dependence to diversification" came to the conclusion that "an increase in the natural share of capital from a country is associated with a decrease in per capita growth" (Gylfason, 2004; Bratianu et al., 2020).

Regarding the impact of natural resources on the economy, there have been several researches that concluded that resources can be both a blessing and a curse. The paradox of the abundance of natural resources (the Dutch Disease) is a very controversial issue. Zuzana Brincikova examined this topic in her study "The Dutch Disease: An Overview" from 2016 and came to the conclusion that you need a transparent democracy and society as well as suitable development channels in order to achieve stable economic growth despite the Dutch Disease. (Brincikova, 2016; Busu et al., 2020).

The relationship between resource rents and a country's economic growth has also been studied by Mehar, Hasan, Sheikh and Adeeb. In their case study, "Total Natural Resources Rent Relation with Economic Growth: The Case of Pakistan and India" (2018), they concluded that total natural resource rents in Pakistan and India have a significant and positive relationship with per capita -BIP of both countries (Mehar et al., 2018).

Hypotheses: The natural resource rents are related to a country's GDP per capita and GDP growth. For the data analysis, several steps were taken in order to be able to question the above hypotheses. Most of the data retrieved were processed on the basis of econometric methods and then analysed and interpreted in an attempt to define a pattern for the selected country categories. 


\section{Data acquisition}

In order to achieve the best possible result for the analysis, the data was retrieved for a period of ten years, with $\mathrm{t} 0=2008$ and $\mathrm{t} 10=2017$. The sample includes 45 countries selected for their classification as high-, middle- or low-income countries.

According to the World Bank, the countries are classified based on their gross national income as follows:

a. A country can be classified as a high-income country if its gross national income (GNI) per capita exceeds USD 12,056. (World Bank, 2020)

b. A country can be classified as a middle-income country if its GNI is between USD 1,026 and USD 12,375. (World Bank, 2020)

c. A country is classified as a low-income country if its GNI is less than $\$ 1,026$. (World Bank, 2020)

The retrieved data relates to the gross domestic product per capita (in USD) of the selected countries, the GDP growth (in\%) of the selected countries and the total natural resource rents (in\% of GDP) of the selected countries. The data was mostly processed and analysed econometrically. This analysis was based on the Pearson correlation coefficient, which was used to establish different relationships between the selected variables for the 45 selected countries, namely:

- High-income countries chosen: Australia, Austria, Belgium, Canada, Croatia, Cyprus, Finland, France, Germany, Greece, Italy, the Netherlands, Singapore, the United Kingdom and the United States;

- Middle-income countries chosen: Angola, Bangladesh, Cameroon, Egypt, Arab Republic, Georgia, Ghana, Indonesia, India, Cambodia, Sri Lanka, Mauritania, Nigeria, Pakistan, Philippines, Vietnam;

- Low-income countries chosen: Benin, Central African Republic, Ethiopia, Guinea-Bissau, Haiti, Liberia, Madagascar, Mozambique, Nepal, Rwanda, Chad, Togo, Tajikistan, Tanzania, Uganda.

\section{Data processing}

Using the Pearson correlation coefficient, the covariance formula of two variables labeled $\mathrm{X}$ and $\mathrm{Y}$ was used to determine whether and what kind of correlations exist between the selected indicators:

$$
\rho_{\mathrm{X}, \mathrm{Y}}=\frac{\operatorname{cov}(X, Y)}{\sigma x \sigma y}, \text { where }
$$

- $\mathrm{Cov}$ is the covariance;

- $\sigma \mathrm{x}$ is the standard deviation of $\mathrm{X}$;

- $\sigma y$ is the standard deviation of Y (Real Statistics, n.d.).

The Pearson correlation coefficient is essentially the covariance of the two variables ( $\mathrm{X}$ and Y) divided by the product of their standard deviations. The coefficient can have values between -1 and +1 and its interpretation is as follows:

- If the Pearson correlation coefficient is close to +1 , the variables $\mathrm{X}$ and $\mathrm{Y}$ are positively correlated. This means that high values of $X$ are associated with high values of $Y$ and low values of $\mathrm{X}$ are associated with low values of $\mathrm{Y}$.

- If the Pearson correlation coefficient is close to -1 , the variables $\mathrm{X}$ and $\mathrm{Y}$ are negatively correlated. This means that high values of $\mathrm{X}$ are associated with low values of $\mathrm{Y}$ and low values of $\mathrm{X}$ are associated with high values of $\mathrm{Y}$. 
- If the Pearson correlation coefficient is close to 0 , there is little (or none) linear relationship between $\mathrm{X}$ and Y. (Real Statistics, n.d.)

However, if the Pearson correlation coefficient takes exactly the values -1 or +1 , one can speak of a perfect correlation, which is very rare.

The variables considered for the purpose of this paper were GDP per capita (in USD), GDP growth (in\%) and total natural resource rents (in\% of GDP). These variables are defined as follows:

- Gross domestic product (GDP) per capita is a metric that breaks down a country's GDP per person. It is calculated by dividing GDP across a country's population. GDP per capita is a universal measure of the prosperity of nations around the world. It is used by economists around the world alongside GDP to analyse a country's prosperity and economic growth. (Chappelow, 2019)

- The GDP growth indicator measures how fast the economy is growing. A quarter of the country's gross domestic product is compared with the previous quarter. The GDP growth rate is determined by the four components of GDP. The main driver of GDP growth is personal consumption, which also includes the critical sector of retail sales. The second component is business investment, including construction and inventory. Government spending is the third growth driver. The largest categories are Social Security Benefits, Defense Spending, and Medicare Benefits. Finally, the fourth component is net trading. (Amadeo, 2020)

- Resource abundance is indicated by the share of resource rents in GDP. The total natural resource rents (\% of GDP) are the sum of oil rents, natural gas rents, coal rents, mineral rents and forest rents. The natural resource rent is the total revenue that can be achieved through the extraction of the natural resource, minus the costs of extracting the resource. (SESRIC, 2011)

\section{Results and discussions}

In order to be able to draw conclusions on the above-mentioned hypotheses, two separate correlation sets were carried out for all three country categories.

a) The first correlation set was carried out between GDP per capita and total natural resource rents (in\% of GDP) for the three country categories.

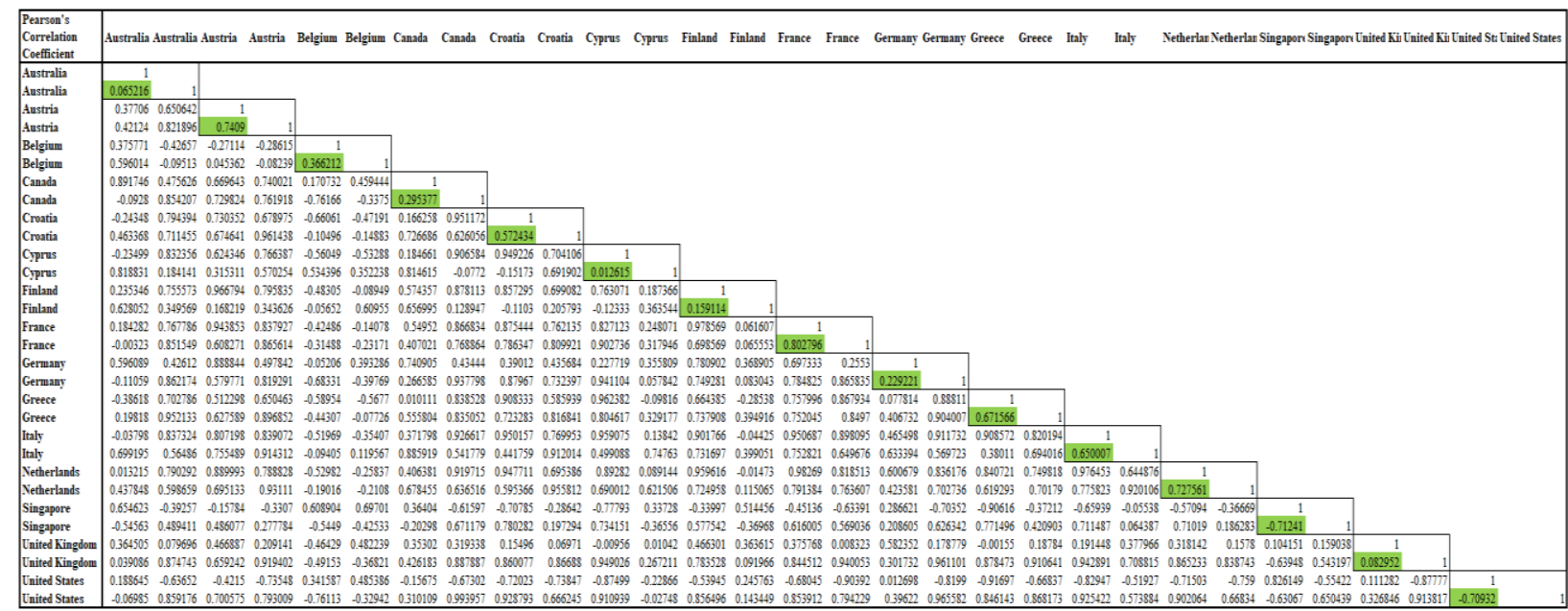

Figure 1. Pearson correlation coefficient between GDP per capita and total natural resource rents for high-income countries

Source: personal calculation based on data retrieved from the World Bank. 
As it can be seen from the above calculation, the majority of high-income countries tend to have a positive correlation between their GDP per capita and the share of natural resources in GDP. France shows the strongest positive correlation, with 0.8028, while Singapore has the strongest negative correlation, with -0.7124 . In other words, France's share of natural resources increases at the same time as GDP per capita, while in Singapore, it is the other way around.

Based on the analysis performed, ten countries showed a positive correlation and two showed a negative relationship. The analysis also indicated three countries for which no correlation could be made between the variables. Taking into account the selected countries, we can say that overall, for high-income countries, the relationship between GDP per capita and the share of natural resources is positive.

\begin{tabular}{|l|c|l|}
\hline \multicolumn{3}{|c|}{ Middle income countries } \\
\hline Angola & 0.06935 & no linear correlation \\
\hline Bangladesh & $(0.71215)$ & strong negative correlation \\
\hline Cameroon & 0.12134 & weak positive correlation \\
\hline Egypt, Arab Rep. & $(0.56262)$ & moderate negative correlation \\
\hline Georgia & $(0.07522)$ & no linear correlation \\
\hline Ghana & $(0.04336)$ & no linear correlation \\
\hline Indonesia & $(0.60077)$ & moderate negative correlation \\
\hline India & $(0.76596)$ & strong negative correlation \\
\hline Cambodia & $(0.81369)$ & strong negative correlation \\
\hline Sri Lanka & $(0.63827)$ & moderate negative correlation \\
\hline Mauritania & 0.44599 & weak positive correlation \\
\hline Nigeria & 0.05152 & no linear correlation \\
\hline Pakistan & $(0.56474)$ & moderate negative correlation \\
\hline Philippines & $(0.31429)$ & moderate negative correlation \\
\hline Vietnam & $(0.83922)$ & strong negative correlation \\
\hline
\end{tabular}

Figure 2. Pearson correlation coefficient between GDP per capita and total natural resource rents for middle-income countries

Source: personal calculation based on data retrieved from the World Bank.

As it can be seen from Table 2, the majority of middle-income countries tend to have a negative relationship between the two selected variables. There is no country that has a moderate or strong positive correlation. On the other hand, nine of the fifteen selected countries show a negative correlation, with Vietnam having the strongest correlation, namely -0.83922 . Cameroon $(0.12134)$ and Mauritania (0.44599) showed weak positive correlations.

Regarding the selected countries, one can therefore conclude that middle-income countries tend to have a negative correlation in terms of the ratio between GDP per capita and natural resource rents. 


\begin{tabular}{|l|c|l|}
\hline \multicolumn{3}{|c|}{ Low income countries } \\
\hline Benin & $(0.30609)$ & moderate negative correlation \\
\hline Central African Republic & $(0.79854)$ & strong negative correlation \\
\hline Ethiopia & $(0.96925)$ & strong negative correlation \\
\hline Guinea-Bissau & $(0.24697)$ & weak negative correlation \\
\hline Haiti & 0.35333 & moderate positive correlation \\
\hline Liberia & 0.68409 & moderate positive correlation \\
\hline Madagascar & $(0.19146)$ & weak negative correlation \\
\hline Mozambique & $(0.37913)$ & moderate negative correlation \\
\hline Nepal & 0.02044 & no linear correlation \\
\hline Rwanda & $(0.86682)$ & strong negative correlation \\
\hline Chad & 0.56884 & moderate positive correlation \\
\hline Togo & 0.19155 & weak positive correlation \\
\hline Tajikistan & 0.00969 & no linear correlation \\
\hline Tanzania & $(0.50042)$ & moderate negative correlation \\
\hline Uganda & $(0.74335)$ & strong negative correlation \\
\hline
\end{tabular}

PICBE | 223

Figure 3. Pearson correlation coefficient between GDP per capita and total natural resource rents for low-income countries

Source: personal calculation based on data retrieved from the World Bank.

Table 3 summarises the calculation of the Pearson Correlation Coefficient for low-income countries. As far as the selected low-income countries are concerned, it can be noted that, they tend to have a negative relationship between the resource share and GDP per capita, behavior which is similar to the selected middle-income countries. Ethiopia shows the strongest negative correlation, namely -0.96925 . In other words, high levels of Ethiopia's GDP per capita are linked to low levels of natural resource rents, and vice versa.

From the results in Table 3 one can conclude that for the majority of the selected countries, there is a negative relationship between the two selected variables, GDP per capita and the share of natural resources.

Using the Pearson correlation coefficient, we tried to create a pattern for the three selected country categories. The results regarding the correlation between GDP per capita and total natural resource rents (as a percentage of GDP) were therefore as follows: The selected high-income countries showed a tendency towards a positive relationship, the selected middle-income countries and those with low incomes, on the other hand, showed a tendency towards negative relationships. Therefore, for this part of the analysis, hypothesis \# 1 was confirmed, namely that resource rents are linked to the GDP per capita of the selected countries.

b) The second correlation set analysed the relationship between the GDP growth (in\%) of the selected countries and the total rents of natural resources (in\% of GDP) to determine whether the share of natural resources with the economic development of the selected countries is correlated. 


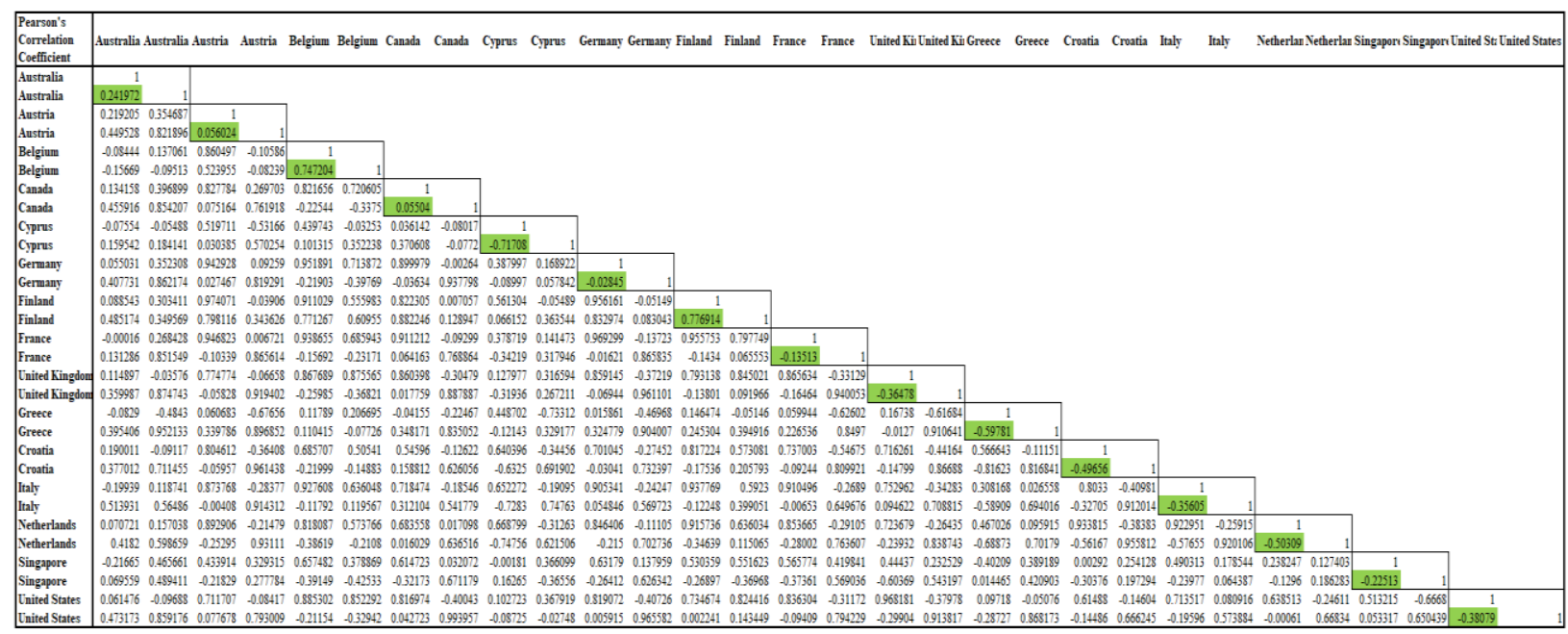

Figure 4. Pearson correlation coefficient between GDP growth and total natural resource rents for high-income countries

Source: personal calculation based on data retrieved from the World Bank.

From Table 4 one can see that the relationship between the two selected variables tends to be negative. The strongest negative correlation was found for Croatia, namely -0.71708 . In other words, this means that an increase in the share of natural resources is associated with low economic growth in the country, and vice versa. The same applies to Greece and Singapore, which have negative correlations of -0.59781 and -0.50309 . However, as it can be seen from the table above, there are two countries that have a strong positive correlation, namely Belgium and Finland, with correlations of 0.74720 and 0.77691 , respectively. For these two countries and also for Australia, an increase in the share of resources is associated with an increase in economic growth.

Taking into account the results of the majority of the selected countries, it can be concluded that the overall ratio between GDP growth and the share of natural resources in high-income countries tends to be negative.

\begin{tabular}{|l|r|l|}
\hline & \multicolumn{2}{|c|}{ Middle income countries } \\
\hline Angola & 0.83400 & strong positive correlation \\
\hline Bangladesh & -0.40482 & moderate negative correlation \\
\hline Cameroon & -0.04422 & no linear correlation \\
\hline Egypt, Arab Rep. & 0.06059 & no linear correlation \\
\hline Georgia & 0.61574 & moderate positive correlation \\
\hline Ghana & 0.56985 & moderate positive correlation \\
\hline Indonesia & 0.67971 & moderate positive correlation \\
\hline India & -0.80292 & strong negative correlation \\
\hline Cambodia & -0.35052 & strong negative correlation \\
\hline Sri Lanka & 0.51265 & moderate positive correlation \\
\hline Mauritania & 0.31723 & moderate positive correlation \\
\hline Nigeria & 0.63198 & moderate positive correlation \\
\hline Pakistan & -0.61795 & moderate negative correlation \\
\hline Philippines & -0.16510 & weak negative correlation \\
\hline Vietnam & -0.47791 & moderate negative correlation \\
\hline
\end{tabular}

Figure 5. Pearson correlation coefficient between GDP growth and total natural resource rents for middle-income countries

Source: personal calculation based on data retrieved from the World Bank. 
As it can be seen from Table 5, the majority of the selected middle-income countries tends to have a positive relationship between the two selected variables. Angola shows the strongest positive correlation, namely 0.83400 . Given that six of the fifteen countries selected show a negative relationship between the two selected variables, no precise conclusion can be drawn on this matter.

\begin{tabular}{|l|r|l|}
\hline \multicolumn{3}{|c|}{ Low income countries } \\
\hline Benin & -0.16176 & weak negative correlation \\
\hline Central African Republic & -0.43507 & moderate negative correlation \\
\hline Ethiopia & 0.33366 & moderate positive correlation \\
\hline Guinea-Bissau & -0.27586 & weak negative correlation \\
\hline Haiti & -0.32849 & moderate negative correlation \\
\hline Liberia & 0.14298 & weak positive correlation \\
\hline Madagascar & 0.24979 & weak positive correlation \\
\hline Mozambique & -0.80637 & strong negative correlation \\
\hline Nepal & -0.30995 & moderate negative correlation \\
\hline Rwanda & 0.68474 & moderate positive correlation \\
\hline Chad & 0.29644 & weak positive correlation \\
\hline Togo & 0.64495 & moderate positive correlation \\
\hline Tajikistan & 0.32321 & moderate positive correlation \\
\hline Tanzania & -0.16281 & weak negative correlation \\
\hline Uganda & 0.34746 & moderate positive correlation \\
\hline
\end{tabular}

Figure 6. Pearson correlation coefficient between GDP growth and total natural resource rents for low-income countries

Source: personal calculation based on data retrieved from the World Bank.

Table 6 summarises the calculation of the Pearson Correlation Coefficient for low-income countries. The entire table can be found in the appendix.

From the table above, it can be seen that the majority of the selected low-income countries tend to have a positive relationship between the two selected variables. In other words, for these countries an increase in the total share of resources is positively associated with an increase in economic development. The highest positive correlation was found for Rwanda, which is 0.68474. However, one cannot neglect the fact that seven of the fifteen countries tend to have a negative relationship between the two selected variables, with the strongest negative correlation of -0.80637 belonging to Mozambique.

Based on the behavior of the majority of low-income countries, it can be said that they tend to have a positive correlation between GDP growth and total natural resource rents. However, no definitive conclusion can be drawn on this issue as this paper does not cover all low-income countries and does not take into account all factors and variables that could affect the outcome of the present analysis.

Using the Pearson correlation coefficient, we tried to create a pattern for the three selected country categories. Therefore, with regard to the relationship between GDP growth and total natural resource rents, the results are as follows: the selected high-income countries tended to show a negative relationship, the selected middle-income and low-income countries tended to show a positive relationship. Therefore, also for this part of the analysis, our hypothesis was confirmed, namely that resource rents are linked to the GDP growth of the selected countries. 


\section{Conclusions}

This paper aimed to determine whether the abundance of resources can be used as an indicator of the economic development of a given country. To this end, the existing literature on the topic under discussion was reviewed in order to develop the basis for the analysis carried out.

The aim of the analysis was to conclude on the discussed topic whether the resources can be correlated with the economic development of the selected countries.

The analysis included two sets of correlations. One was done between a country's resource

rents as a percentage of its GDP and GDP per capita, and the second set of correlations was done between a country's resource rents and GDP growth.

In this paper, it was found that resource rents and the above two variables are correlated by having either positive or negative relationships.

As far as the high-income countries are concerned, it was noted that resource rents and their GDP per capita correlate positively, meaning that high values of resource rents are associated with high values of GDP per capita in the selected countries. However, regarding the correlation between resource rents and GDP growth of the selected countries, these variables were found to be negatively correlated. In other words, resource rents in the selected high-income countries have two types of correlation with GDP per capita and GDP growth, respectively.

Regarding the selected middle-income countries, the analysis showed that for the majority of the selected countries, resource rents and their GDP per capita correlate negatively. Regarding the correlation between resource rents and GDP growth, it was found that seven of the selected countries tend to have a positive relationship between the two selected variables. However, the fact that six of the fifteen selected countries have a negative relationship between the two selected variables cannot be neglected. Consequently, no clear conclusion could be drawn from the analysis. Regarding the selected low-income countries, it was found that for the majority of the selected countries, resource rents and their GDP per capita correlate negatively. In other words, either high values of resource rents are associated with low values of GDP per capita in the selected countries, or low values of resource rents are associated with high values of GDP per capita. However, regarding the correlation between resource rents and GDP growth in the selected countries, it was found that the selected variables tend to have a positive relationship, which is exactly the opposite of the correlation between resource rents and GDP per capita.

The analysis did not provide any insight into the causal relationship between the selected variables, only to the extent that they vary with one another.

The results in this paper are not intended as a theory or pattern. The results may vary from country to country and can be influenced by various factors that are not considered in this paper. This paper aimed to establish certain correlations between the selected variables for the 45 selected countries. In order to achieve a clearer and generally valid result, the topic discussed should be further investigated and the analysis should be extended to other countries. A broader analysis should also take into account the other factors that are known to affect the economic development of a given country, such as a country's political stability, its macroeconomic stability, its level of infrastructure and others.

\section{References}

Amadeo, K. (2020). The Balance. Website: https://www.thebalance.com/what-is-the-gdp-growthrate-3306016.

Amoah, J., Belás, J., Khan, K. A., Metzker, Z. (2021). “Antecedents of Sustainable SMEs in the Social Media Space: A Partial Least Square-Structural Equation Modeling (PLS-SEM) 
Approach”, Management \& Marketing. Challenges for the Knowledge Society, Vol. 16, No. 1, 26-46, DOI: 10.2478/mmcks-2021-0003.

Bratianu, C., Prelipcean, G., and Bejinaru, R. (2020). "Exploring the latent variables which support SMEs to become learning organizations", Management \& Marketing. Challenges for the Knowledge Society, 15(2), 154-171, DOI: 10.2478/mmcks-2020-0010.

Brincikova, Z. (2016). The Dutch Disease: An Overview, European Scientific Journal, ESJ 12(10), DOI: https://doi.org/10.19044/esj.2016.v12n10p\%25p.

Busu, M., Vargas, M.V., Gherasim, I.A. (2020). "An analysis of the economic performances of the retail companies in Romania", Management \& Marketing, Challenges for the Knowledge Society, 15(1), 125-133, DOI: 10.2478/mmcks-2020-0008.

Cobb, C., Halstead, T., \& Rowe, J. (1995). If the GDP is Up, Why is America Down?. Im Internet unter: https://www.theatlantic.com/past/docs/politics/ecbig/gdp.htm.

Chappelow, J. (2019). Investopedia. Im Internet unter: https://www.investopedia.com/terms/p/percapita-gdp.asp. Stand: 23 Mai 2020.

Frumkin, N. (2006). Guide to economic indicators $-4^{\text {th }}$ edition. London and New York: Routledge Taylor \& Francis Group.

Gylfason, T. (2004). Natural Resources and economic growth: from dependence to diversification, s.1.: University of Iceland and Centre for Economic Policy Research.

Kim, D.-H., \& Lin, S.-C. (2017). Natural resources and economic development: new panel evidence, Environment \& Resource Economics.

Mehar, M., Hasan, A., Sheikh, M. A., \& Adeeb, B. (2018). Total Natural Resources Rent Relation with Economic Growth: The case of Pakistan and India, European Journal of Economic and Business, 3(3), 14-22.

Real Statistics website: http://www.real-statistics.com/correlation/basic-concepts-correlation/.

SESRIC (2009). Official website: https://www.sesric.org/DidYouKnow/doc/NATURAL\%20RE SOURCES\%20RENTS_2009.pdf.

Trumel, R., \& Muhammad, A. N. (2020). Role of natural resource abundance, international trade and financial development in the economic development of selected countries, Resources Policy.

World Bank. Official website: https://worldpopulationreview.com/countries/high-incomecountries.

World Bank. Official website: https://worldpopulationreview.com/countries/middle-incomecountries/.

World Bank. Official website: https://worldpopulationreview.com/countries/low-incomecountries/\#dataTable.

Yanikkaya, H., \& Turan, T. (2018). Curse or blessing? An empirical re-examination of natural resource-growth nexus, Journal of International Development. 